\title{
Breaking Patient Confidentiality: Comparing Chilean and French Viewpoints Regarding the Conditions of its Acceptability
}

\author{
La ruptura de la confidencialidad: una comparación \\ entre las perspectivas chilena y francesa respecto \\ a las condiciones de su aceptabilidad
}

Recibido: noviembre 22 de 2009 | Revisado: enero 19 de 2010 | Aceptado: abril 23 de 2010

\author{
Cecilia Olivari** \\ Catholic University of Maule, Chile \\ Maria Teresa MuÑoz Sastre**** \\ MYRIAM GUEDJ \\ Mirail University, Toulouse, France \\ PAUl Clay SORUM ${ }^{* * * * *}$ \\ Albany Medical College, New York, EE.UU. \\ ETIENNE MULLET ${ }^{* * * * * *}$ \\ Institute of Advanced Studies (EPHE), Paris, France
}

Para citar este artículo. Olivari, C., Muñoz, M. T., Guedj, M., Sorum, P. C., \& Mullet, E. (2011). Breaking patient confidenciality: comparing Chilean and French viewpoints regarding the conditions of its acceptability. Universitas Psychologica, 10 (1), 13-26.

* Research article.

** Casilla 617. Talca. Chile. E-mail: colivari@ucm.cl

**** Université de Toulouse II - Le Mirail, Bureau R39, Rez-de-chaussée du Pavillon de la Recherche. Emails:munoz@univ-tlse2.fr; guedj@univ-tlse2.fr

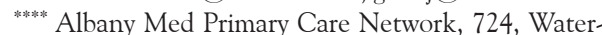
vliet-Shaker Road, Latham, NY 12110, United States of America.E-mail: sorump@mail.amc.edu

***** Corresponding author: Etienne Mullet, Quefes 17bis, F-31830 Plaisance, France, etienne.mullet@ wanadoo.fr

\begin{abstract}
A B S T R A C T
To examine the conditions under which lay people and health professionals living in Chile and France find it acceptable for a physician to break confidentiality to protect the spouse of a patient with a sexually transmitted disease (STD), 207 lay persons and healthcare professionals indicated the acceptability of breaking confidentiality in 48 scenarios combining five factors: disease severity, time taken to discuss this with the patient, patient's intent to inform his spouse about the disease, patient's intent to adopt protective behaviors, and physician's decision to consult an STD expert. A cluster analysis revealed groups that found breaking confidentiality "always acceptable", requiring "consultation with an expert", "depending on the many circumstances", and "never acceptable" (11\%)". Despite differences in legislation and ethics codes, Chilean and French lay people showed similar personal convictions regarding the circumstances in which breaking patient confidentiality is acceptable. In contrast, Chilean physicians were much less supportive than French physicians of complete respect of patient confidentiality in all cases.

Key words authors

Confidentiality, Patient-Physician Relationship, Sexually Transmitted Disease, Spousal Abuse, Chile, France.

Key words plus

Confidential Communications, Physician and Patient, Sexually Transmitted

Diseases, Conjugal Violence, Chile.

\section{RESUMEN}

Para examinar las condiciones bajo las cuales una muestra de participantes del público general y de profesionales de la salud chilenos considera aceptable que un médico rompa la confidencialidad para proteger al cónyuge de un paciente que padece una enfermedad de transmisión sexual (ETS), doscientos siete participantes (personas del público general y profesionales de la salud), evaluaron la aceptabilidad de dicha ruptura en 48 escenarios, que consistieron en todas las posibles combinaciones de 5 factores (gravedad de la enfermedad, tiempo que se toma conversar sobre la enfermedad con
\end{abstract}


el paciente, intento del paciente por informar a su cónyuge sobre su enfermedad, intento del paciente por adoptar una conducta de protección hacia su cónyuge, y decisión del médico de consultar a un especialista en ETS). Un análisis de racimos reveló grupos de participantes que encontraron la ruptura de la confidencialidad oscilando entre "siempre aceptable" y "nunca aceptable". A pesar de las diferencias de legislación y códigos de ética, las muestras de público general no difirieron mucho en sus convicciones personales respecto a las circunstancias de protección o ruptura de la confidencialidad del paciente. En contraste, los médicos chilenos apoyaron menos que los franceses mantener un completo respeto a la confidencialidad del paciente en todos los casos. Palabras clave autores

Confidencialidad relación médico-paciente, enfermedad sexualmente transmisible, violencia de pareja, Chile, Francia. Palabras clave descriptores

Comunicaciones confidenciales, médico y paciente, enfermedades de transmisión sexual, violencia conyugal, Chile.

The study compared the attitudes of lay people and health professionals in Chile and France concerning the breaking of confidentiality by physicians who suspect that their patients are going to put the health and lives of others in danger. It also compared the public's and the caregivers' attitudes in both countries.

Confidentiality is an ethical cornerstone of physician-patient relationships. Confidentiality ensures trust. Trust facilitates complete disclosure of personal and sometimes sensitive information. Complete information allows more rapid and accurate diagnosis and, as a result, more rapid and effective treatment. Confidentiality plays, therefore, an indisputable role in the treating and healing process. Its importance was recognized in the earliest codes of medical conduct (Edelstein, 1943).

\section{Conflicting Values}

Nonetheless, confidentiality has its limits; that is, the value of confidentiality can conflict with the value of life itself. When physicians suspect that their patients' lack of concern for others or downright hostility towards them will put these persons at risk, they face a dilemma. Should they maintain confidentiality? Should they break confidentiality in view of protecting the other persons? The answers given in the laws and medical codes of ethics differ, however, from a country to the other.
In Chile, patient confidentiality is protected by the Code of Ethics elaborated by the medical corps itself (Colegio Médico de Chile, 2008). Article 31 states that physicians must respect the confidentiality of any information regarding the patients, whether it has been obtained through verbal exchange with them or through laboratory exams and surgical procedures. It is, however, considered legitimate to breach confidentiality in some cases that include (a) illnesses that must legally be declared to the authorities (e.g., syphilis), (b) court decisions, (c) certifications of birth and death, and (d) when disclosure is necessary to avoid severe harm to the patient or to other persons. For the breaking of confidentiality being considered legitimate, a deliberation involving several persons is necessary. Article 247 of the Chilean Penal Code (Código Penal, 2008) states that civil servants or professionals who reveal personal information are to be condemned to short term imprisonment, and to pay a fine that can amount to ten times their monthly income. Article 175 of the Chilean Penal Procedural Code states that health professionals have the obligation to report any fact that may constitute breaking a law (Código Procesal Penal, 2009).

In France, by contrast, the emphasis is on preserving patient confidentiality. According to $\mathrm{Ar}$ ticle 4 of the Code of Medical Ethics promulgated by the medical corps itself (Conseil National de l'Ordre des Médecins, 1996), "professional confidentiality, instituted in patients' interest, is obligatory for every physician within the conditions established by law. Confidentiality applies to everything the physician learns in the exercise of his profession, which is to say not only what has been confided to him, but also what he has seen, heard or understood." According to Article 226-13 of the French penal code (Nouveau Code Pénal, 2002), "The revelation of confidential information by a person who possesses it either by profession or by reason of a function or of a temporary mission is punished by one year of prison and a fine of 15,000 euros.".

When it involves the possible transmission of a lethal sexually transmitted disease to a close 
partner, the issue of confidentiality becomes particularly sensitive. In Chile, the confidentiality of a patient's infection with HIV is strictly protected by the law (Law 19.779), which stipulates that health professionals who analyze the fluids and communicate the information must absolutely respect confidentiality. In France, the confidentiality of a patient's infection with HIV is also strictly protected. The Ordre des Médecins (Conseil National de l'Ordre des Médecins, 1996) stated that physicians are not authorized to reveal anything to the partner of an infected patient as long as this patient opposes any revelation.

\section{Professionals and Patients' Views as Regards Confidentiality}

Several studies have examined health professionals' views about the breaking of confidentiality in cases of HIV infection. In the United States, health professionals usually agree with the idea that the value of life is higher than the value of confidentiality (e.g., DiMarco \& Zoline, 2004; Keffala \& Stone, 1999; McGuire, Nieri, Abott \& Fisher, 1995; Stewart \& Repucci, 1994). Their judgments about the acceptability of breaking confidentiality conformed to the principle of the Tarasoff decisions (Totten, Lamb \& Reeder, 1990). In France, Moatti et al. (1995) showed that general practitioners were hostile to the idea of breaking confidentiality. Their judgments conformed to the statements of the Ordre des Médecins.

The attitudes of the general public about breaking patient confidentiality have been little studied. Jones (2003) asked 30 consecutive patients living in England if confidentiality should be breached in five scenarios and found considerable support for breaking confidentiality to protect third parties, including 50\% who decided that, in the case of a man with an STD who would not tell his wife, the doctor should tell her.

Guedj, Muñoz Sastre, Mullet and Sorum (2006) examined the impact of five factors on acceptability judgments among French lay persons: (a) the level of the patient's dangerousness for the other person (in this case, his wife); (b) the patient's in- tent to inform and (c) to protect this other person; (d) the time taken by the doctor to discuss the issue with the patient; and (e) the advice received from another, more expert doctor. The relative impact of these five factors was examined in the specific context of a husband found to have an STD. The authors created a set of 48 scenarios by orthogonally combining these factors, which allowed them to assess the relative impact of each factor and easily detect possible interactions between factors.

A cluster analysis revealed four very different clusters. The first cluster, which comprised about 9\% of the participants, was named Always acceptable because acceptability ratings were always close to the maximum value. The second cluster, which comprised about 20\% of the participants, was named Consulting an Expert because consultation with an expert in STD was the only factor to have an impact on acceptability judgments. The third cluster, which comprised about $60 \%$ of the participants, was named Depending on the Many Circumstances. Its mean acceptability rating was close to the mid-point of the scale, and all five factors had an impact. The two most important factors were the patient's intention to adopt protective behavior and the patient's intention to inform the person at risk (the patient's spouse). The fourth cluster, which comprised about $8 \%$ of the participants, was called Never acceptable because the acceptability ratings were always close to the minimum value. There were no important differences in the composition of the clusters according to age, gender, or educational level.

Guedj et al. (2006) also included in their study small samples of physicians and psychologists. In their acceptability judgments, lay participants and psychologists differed greatly from physicians. For most physicians, breaking confidentiality was in all cases unacceptable.

Guedj, Muñoz Sastre, Mullet and Sorum (2009) conducted a second study regarding the acceptability for a psychiatrist to break confidentiality to protect the wife of a potentially violent patient. As in the 2006 study, the 48 scenarios were all combinations of five factors: (a) gravity of threat (death or beating), (b) certainty of mental illness 
(certain or not), (c) time spent talking with patient (considerable or little), (d) his attitude toward psychotherapy (rejection, indecision, or acceptance), and (e) whether the physician consulted an expert. Lay people favored breaking confidentiality more than did nursing personnel or psychologists. From all the factors considered, consulting an expert had greatest impact. As in the 2006 study, several distinct clusters of lay participants were found: Always acceptable, Requiring consultation with an expert, Depending on many circumstances (the majority cluster), and Never acceptable.

Synthesizing the findings from both studies, Guedj et al. (2009) concluded that lay people were well aware that, when a threat might result in serious injury or illness or even death, decisions about breaking confidentiality are not clear-cut, are fraught with moral complexity and ambiguity, are dependent on the particular circumstances, and require discussion with outside experts. Lay people in France appear, in general, to think more in accordance with Anglo-American than with French laws, legal decisions, and medical ethical dictums.

\section{The Present Study}

The present study was aimed at studying crosscountry differences in ethical judgment in the case of breaking patient confidentiality. As illustrated in the previous section, several studies have been conducted on this issue in different countries, but comparing their results is somewhat difficult because these studies used different techniques and aimed at different objectives. For instance, some studies were only concerned with knowing what percentage of respondents were for or against the breaking of confidentiality (e.g., Moatti et al., 1995), and other studies focused instead on the mental processes by which people make such judgments (Guedj et al., 2006, 2009).

When the laws and official codes of ethics about a specific ethical issue differ between two countries, comparing the views on it of lay people and professionals in one country with those in the other allows determining the extent to which official positions are associated with lay people's beliefs and professionals' decisions. As indicated earlier, Chilean official positions are similar to those in the United States and the United Kingdom, and differ considerably from those in France.

In the present study we gathered data on a sample of Chilean lay people and on three samples of Chilean health professionals using the same material as that used by Guedj et al. (2006) and compared these data with the findings of Guedj et al. (2006). Our first hypothesis, based on the studies by Jones (2003) and Guedj et al. (2006), was that, despite clear differences in legislation and official codes of ethics between their two countries, Chilean and French lay people would not differ much in their intimate convictions regarding the conditions in which patient confidentiality can be broken or must not be broken. Our second hypothesis was that Chilean and French physicians' judgments would, by contrast, strongly differ: Chilean physicians would be much less supportive than French physicians of complete respect of patient confidentiality in all cases.

\section{Method}

As in Guedj et al. (2006, 2009), and as in several other studies on ethical judgment (e.g., Muñoz Sastre, Pecarisi, Legrain, Mullet \& Sorum, 2007; Teisseyre, Mullet \& Sorum, 2005), the methodology was an application of the Functional Theory of Cognition of Norman Anderson (2008). This methodological framework has been shown to provide data that have ecological validity (Fruchart, Rulence-Pâques \& Mullet, 2007; Levin, Louviere, Schepanski \& Norman, 1983). It seems also to be resistant to goal-framing effects that could affect the observed impact of each descriptive factor (Muñoz Sastre, González, Lhermitte, Sorum \& Mullet, in press).

The primary aim of Anderson's methodology is to reveal the cognitive rules used by people to integrate information when they make a judgment or decision. It assumes that people place subjective values on different pieces of information and that they combine these subjective values by means of 
a cognitive algebra dominated by addition, multiplication, and averaging. It studies how they do this indirectly and functionally, i.e. it infers from people's judgments of the combined value of two or more stimuli (or pieces of information) the cognitive rules used to arrive at these judgments.

In Anderson's methodology, participants evaluate combinations of factors, rather than single factors. Accordingly, participants were presented with a series of patient vignettes rather than with a questionnaire and thereby were able to simulate the way the issue would appear in real life-in the context of concrete patients with particular characteristics. Anderson's methodology requires, in addition, a complete factorial design, i.e., our set of vignettes had to consist of all possible combinations of the within-subjects factors. This design not only facilitates the determination of the impact of each factor on the overall judgments, but is necessary for the investigation of their interactions and of the cognitive rules participants have used in combining them. Furthermore, Anderson found that the true importance for people of each factor and the cognitive rules they employed were revealed better by stable rather than by momentary judgments of combined values. His methodology also requires, therefore, that participants become familiar with the task and with these combinations of variables in a "familiarization" phase before they give a final set of judgments.

\section{Participants}

The lay participants were unpaid volunteers recruited and tested by one of the authors (CO). She contacted 250 people in the cities of Talca and Concepción, explained the study, asked them to participate, and, if they agreed, arranged where and when to administer the experiment. Of these, 169 (68\%) participated. She also contacted 30 psychologists and 30 physicians working in private offices or in the main hospital of Concepción, and in primary care centers in Talcahuano and Concepción. Of these, 17 and 10 participated. Because the recruitment of physicians was difficult, she added a sample of 11 other health professionals. The de- mographic characteristics of the Chilean samples as well as of the comparable French samples are shown in Table 1.

\section{Material}

The material consisted of 48 cards containing a story of a few lines, a question, and a response scale. The vignettes were composed according to a five within-subject factor design: the severity of the transmissible disease (severe, lethal) $\mathrm{x}$ the time taken to discuss with the patient about the severity of the disease (little time, much time) x the level of intent to inform the spouse about the disease (no intent to inform, intent to inform one of these days, intent to inform immediately) $\mathrm{x}$ the intent to adopt protective behaviors (no intent, intent) $\mathrm{x}$ the decision to consult an expert in STDs (call to an expert, no call to an expert), $2 \times 2 \times 3 \times 2 \times 2$. Other information was held constant: notably, all patients were males, and in each case the doctor decided to call personally the patient's partner in order to inform her that her husband had an STD. No specific STDs were mentioned in the vignettes.

Under each vignette were a question- "To what extent do you believe that the decision made by the doctor is acceptable?"- -and a large $22-\mathrm{cm}$ linear response scale with anchors of "Not acceptable at all" and "Completely acceptable." Two examples are given in the Appendix. The cards were arranged by chance and in a different order for each participant. Finally, the participants answered additional questions about age, gender, educational level, religious belief, and religious background.

\section{Procedure}

The site was, for the lay people, a vacant university classroom, and for the professionals, their office or a vacant hospital room. Each person was tested individually. The session had two phases. In the familiarization phase, after the experimenter explained what was expected, the participant read each vignette out loud, was reminded by the experimenter of the items of information in it, and indicated on the response scale the acceptability of 
TABLE 1

Results of the cluster analysis and demographic characteristics

\begin{tabular}{|c|c|c|c|c|c|c|c|}
\hline \multirow[b]{2}{*}{ Groups } & \multicolumn{5}{|c|}{ Clusters } & \multirow[b]{2}{*}{ Unclassifiable } & \multirow[b]{2}{*}{ Total } \\
\hline & Never & Expert & Depending & Inverse & Always & & \\
\hline \multicolumn{8}{|c|}{ Chile } \\
\hline Lay Persons & $4(2 \%)$ & $9(5 \%)$ & 125 (74\%) & $5(3 \%)$ & $21(12 \%)$ & $5(3 \%)$ & 169 \\
\hline Psychologists & $1(6 \%)$ & $0(0 \%)$ & $15(88 \%)$ & $0(0 \%)$ & $1(6 \%)$ & $0(0 \%)$ & 17 \\
\hline Physicians & $1(10 \%)$ & $0(0 \%)$ & $7(70 \%)$ & $0(0 \%)$ & $2(20 \%)$ & $0(0 \%)$ & 10 \\
\hline Paramedics & $3(27 \%)$ & $0(0 \%)$ & $8(73 \%)$ & $0(0 \%)$ & $0(0 \%)$ & $0(0 \%)$ & 11 \\
\hline Total & $9(4 \%)$ & $9(4 \%)$ & 155 (75\%) & $5(2 \%)$ & 24 (12\%) & $5(2 \%)$ & 207 \\
\hline Mean Age & 37 & 37 & 32 & 44 & 40 & 46 & 34 \\
\hline Females & $56 \%$ & $56 \%$ & $65 \%$ & $80 \%$ & $67 \%$ & $60 \%$ & $64 \%$ \\
\hline \multicolumn{8}{|c|}{ France } \\
\hline Lay Persons & $14(10 \%)$ & $10(7 \%)$ & 100 (69\%) & $3(2 \%)$ & $14(10 \%)$ & $3(2 \%)$ & 144 \\
\hline Psychologists & $4(40 \%)$ & $1(10 \%)$ & $3(30 \%)$ & $0(0 \%)$ & $2(20 \%)$ & $0(0 \%)$ & 10 \\
\hline Physicians & $6(86 \%)$ & $0(0 \%)$ & $1(14 \%)$ & $0(0 \%)$ & $0(0 \%)$ & $0(0 \%)$ & 7 \\
\hline Total & $24(15 \%)$ & $11(7 \%)$ & $104(65 \%)$ & $3(2 \%)$ & $16(10 \%)$ & $3(2 \%)$ & 161 \\
\hline Mean Age & 29 & 36 & 29 & 30 & 36 & 33 & 31 \\
\hline Females & $50 \%$ & $64 \%$ & $69 \%$ & $100 \%$ & $63 \%$ & $100 \%$ & $66 \%$ \\
\hline \multicolumn{8}{|c|}{ Overall } \\
\hline Total & $33(9 \%)$ & $20(5 \%)$ & 259 (70\%) & $8(2 \%)$ & 40 (11\%) & $8(2 \%)$ & 368 \\
\hline Mean Age & 31 & 36 & 31 & 39 & 38 & 42 & 33 \\
\hline Females & $52 \%$ & $60 \%$ & $66 \%$ & $88 \%$ & $65 \%$ & $75 \%$ & $65 \%$ \\
\hline
\end{tabular}

Source: Own Work.

breaking confidentiality. After completing the 48 ratings, the participant was allowed to look back at, compare, and change his or her responses. In the experimental phase, the participant worked at his or her own pace, but was not allowed to look back at and change previous responses. In both phases, the experimenter made certain that each subject, regardless of age, educational level, or professional status, was able to understand all the necessary information before making a rating.

Both the lay people and the professionals took 30-45 minutes to complete both phases. The ex- perimental phase went quickly because they were already familiar with the task and the material. No lay person or professional complained about the number of vignettes or about their credibility.

\section{Results}

As clearly distinct clusters had been evidenced in previous similar studies (Guedj et al., 2006, 2009), a cluster analysis was conducted on the whole set of data gathered in Chile and in France. A fivecluster solution was selected, as shown in Table 1. 
The first cluster was called Never acceptable. As can be seen in Figure 1 (top panels), the mean acceptability rating of the participants in this cluster was very low. Fifteen percent of French participants were in this cluster but only $4 \%$ of Chilean $(p<$ $.001)$, and this difference was especially large for psychologists (40\% of French versus $6 \%$ of Chilean) and physicians (86\% versus $10 \%)$. Only one Chilean physician was a member of this cluster.

The second cluster was called Requiring consultation with an expert. As can be seen in Figure 1 (middle panels), the mean acceptability rating of the participants in this cluster was close to the middle of the acceptability scale. Except for one French psychologist, the participants in this cluster were all lay people ( $5 \%$ of the Chilean lay people and $7 \%$ of the French). An ANOVA was conducted on the raw data. The design was Decision to consult an expert $\mathrm{x}$ Intent to adopt protective behaviors $x$ Intent to inform the spouse about the disease $\mathrm{x}$ Time taken to discuss with the patient $\mathrm{x}$ Severity of the transmissible disease, $2 \times 2 \times 3 \times 2$ $\mathrm{x} 2$. The results are shown in Table 2 (upper part).

FIGURE 1

Pattern of results for the first three clusters: Never Acceptable (top panels), Requiring Consultation with and Expert (center panels), and Depending on the Many Circumstances (bottom panels).

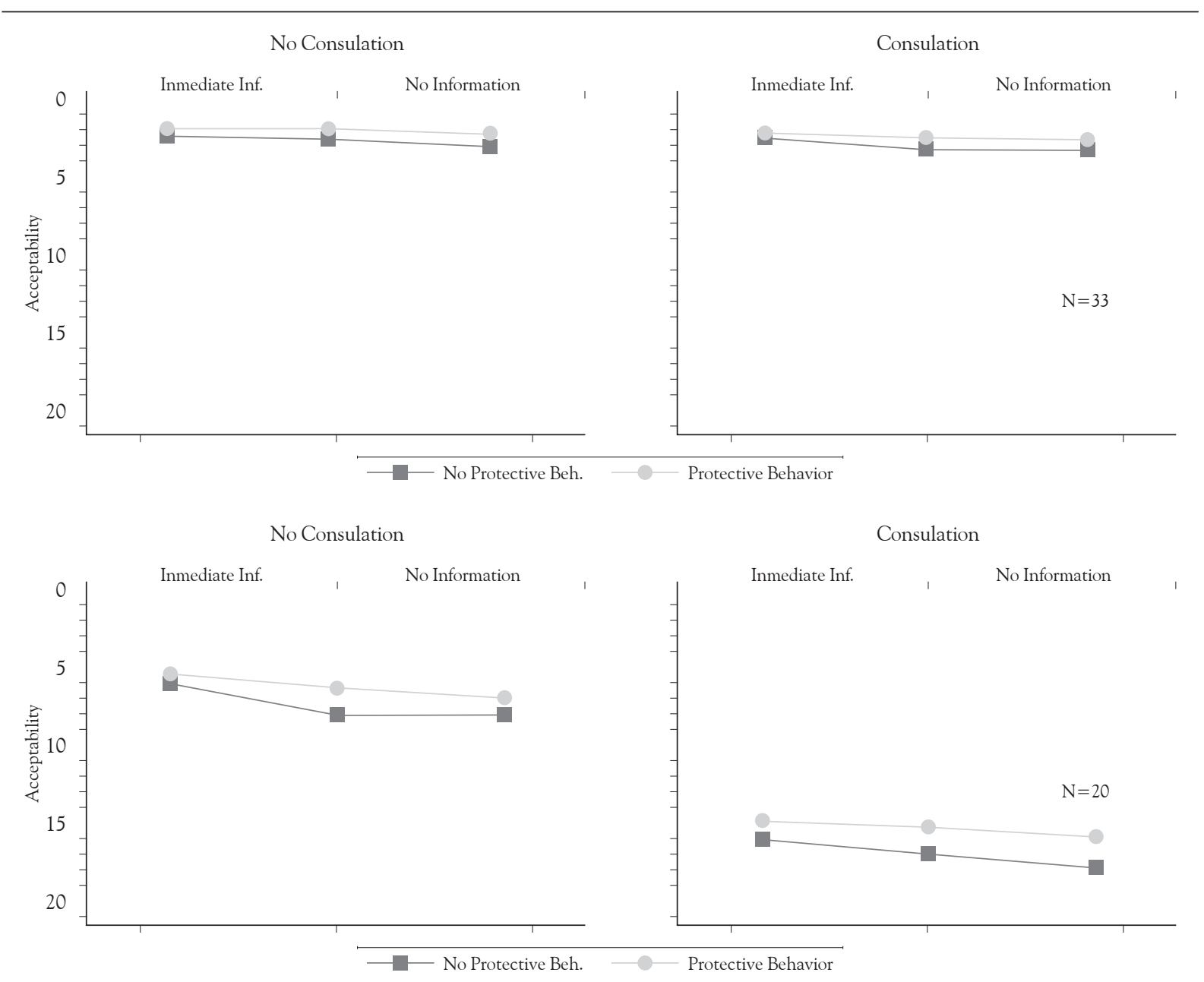




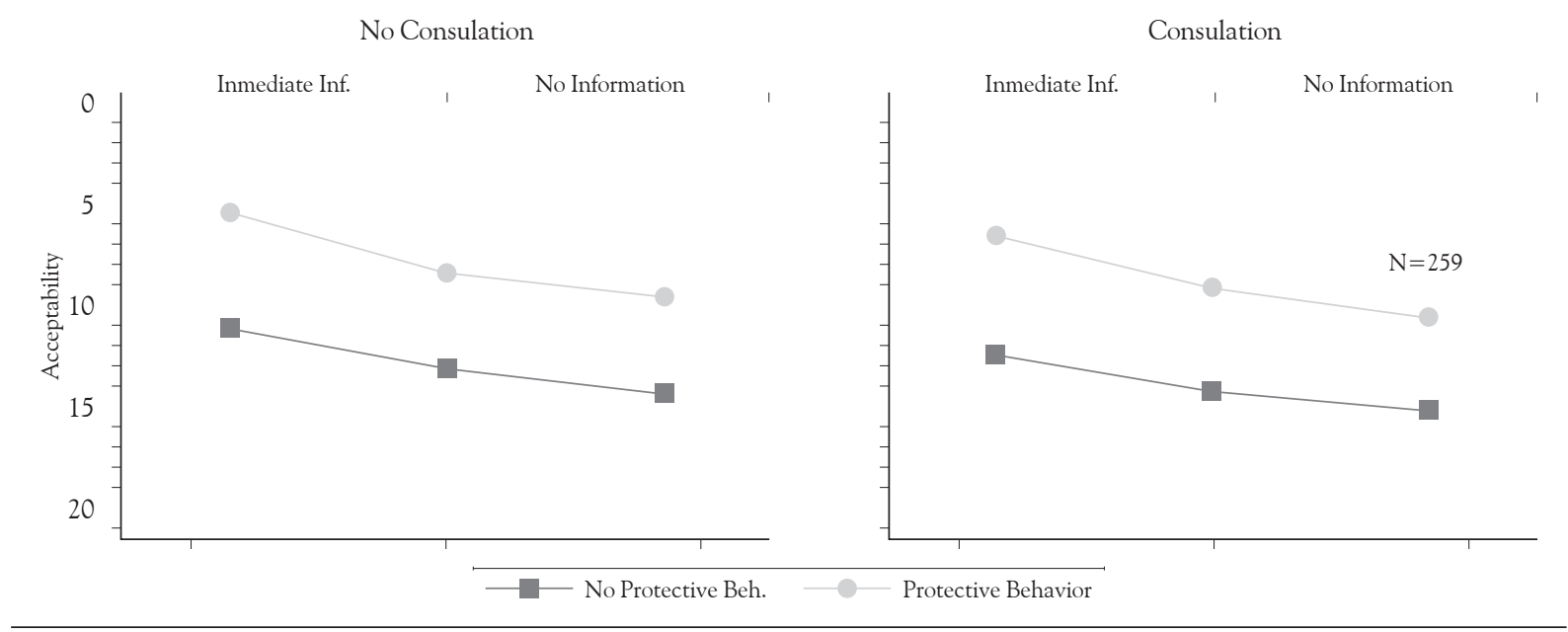

Source: Own work.

TABLE 2

Results of the ANOVAS performed on three clusters

\begin{tabular}{|c|c|c|c|c|c|c|c|}
\hline \multirow[b]{2}{*}{ Factors } & \multicolumn{2}{|c|}{ Effect } & \multicolumn{2}{|c|}{ Error } & \multirow[b]{2}{*}{ F } & \multirow[b]{2}{*}{$p$} & \multirow[b]{2}{*}{$E t a^{2} p$} \\
\hline & $d f$ & MS & $d f$ & MS & & & \\
\hline & \multicolumn{7}{|c|}{ Requiring Consultation with an Expert } \\
\hline Country & 1 & 753.78 & 18 & 135.31 & 5.57 & ns & .13 \\
\hline Expert & 1 & 21905.66 & 18 & 76.62 & 285.89 & .001 & .94 \\
\hline Protection & 1 & 419.74 & 18 & 74.30 & 5.65 & ns & .13 \\
\hline Information & 2 & 209.06 & 36 & 31.64 & 6.61 & ns & .16 \\
\hline Time & 1 & 119.35 & 18 & 18.87 & 6.32 & ns & .15 \\
\hline \multirow[t]{2}{*}{ Severity } & 1 & 5.73 & 18 & 15.53 & 0.37 & ns & .02 \\
\hline & \multicolumn{7}{|c|}{ Depending on the Many Circumstances } \\
\hline Country & 1 & 3.33 & 257 & 435.13 & 0.01 & ns & .00 \\
\hline Expert & 1 & 3544.90 & 257 & 42.10 & 84.20 & .001 & .27 \\
\hline Protection & 1 & 92785.79 & 257 & 166.19 & 558.33 & .001 & .68 \\
\hline Information & 2 & 14981.67 & 514 & 70.64 & 212.08 & .001 & .45 \\
\hline Time & 1 & 1723.63 & 257 & 45.79 & 37.65 & .001 & .13 \\
\hline Severity & 1 & 4322.22 & 257 & 43.54 & 99.28 & .001 & .28 \\
\hline \multirow[t]{2}{*}{ Protection $\mathrm{x}$ Time } & 1 & 823.69 & 257 & 15.09 & 54.57 & .001 & .18 \\
\hline & \multicolumn{7}{|c|}{ Depending on the Many Circumstances (Inverse) } \\
\hline Country & 1 & 24.54 & 6 & 64.52 & 0.38 & ns & .06 \\
\hline Expert & 1 & 96.62 & 6 & 15.03 & 6.43 & ns & .52 \\
\hline
\end{tabular}




\begin{tabular}{lcccccccc}
\hline & \multicolumn{2}{c}{ Effect } & \multicolumn{2}{c}{ Error } & & & \\
\cline { 2 - 5 } \multicolumn{1}{c}{ Factors } & $d f$ & MS & $d f$ & MS & $F$ & $p$ & $E t a^{2} p$ \\
\hline Protection & 1 & 6781.68 & 6 & 482.77 & 14.05 & 0.001 & .70 \\
Information & 2 & 155.71 & 12 & 63.89 & 2.44 & $n s$ & .29 \\
Time & 1 & 438.91 & 6 & 239.99 & 1.83 & $n s$ & .23 \\
Severity & 1 & 108.35 & 6 & 50.41 & 2.15 & $n s$ & .26 \\
\hline
\end{tabular}

Source: Own work.

The third cluster was called Depending on the many circumstances. As can also be seen in Figure 1 (bottom panels), the mean acceptability rating of the participants in this cluster was close to the middle of the acceptability scale. The percentage of Chilean participants in this cluster $(75 \%)$ was higher than the percentage of French participants $(65 \%, p<.05)$. Most Chilean health professionals ( $88 \%$ of psychologists and $70 \%$ of physicians) were members of this cluster versus only a minority of French health professionals (30\% of psychologists and $14 \%$ of physicians; that is, only 1 physician). An ANOVA with the same design was conducted on the raw data. The results are shown in Table 2 (center part). All factors had significant effects, and the protective behavior factor, the intent to inform factor, and the severity of the disease factor had the higher effect sizes.

The fourth cluster was an unexpected small cluster, composed of 5 lay people (\%) in Chili and 3 lay people in France. It was called Depending on the many circumstances (inverse) because, as can be seen in Figure 2 (top panels), the direction of some of the effects was the inverse of the one that was expected. The more the patient intended to inform and protect his wife, the more the breaking of confidentiality was judged acceptable. The results of the ANOVA conducted on the data from this cluster are shown in Table 2 (bottom part). The effect sizes indicate that this cluster was similar to the third one except for the direction of the effects. It was mostly composed of female participants who were somewhat older than the other participants.

Figure 2

Pattern of results for the fourth and fifth clusters: Depending on the Many Circumstances (Inverse) (top panels), and Always Acceptable (bottom panels).

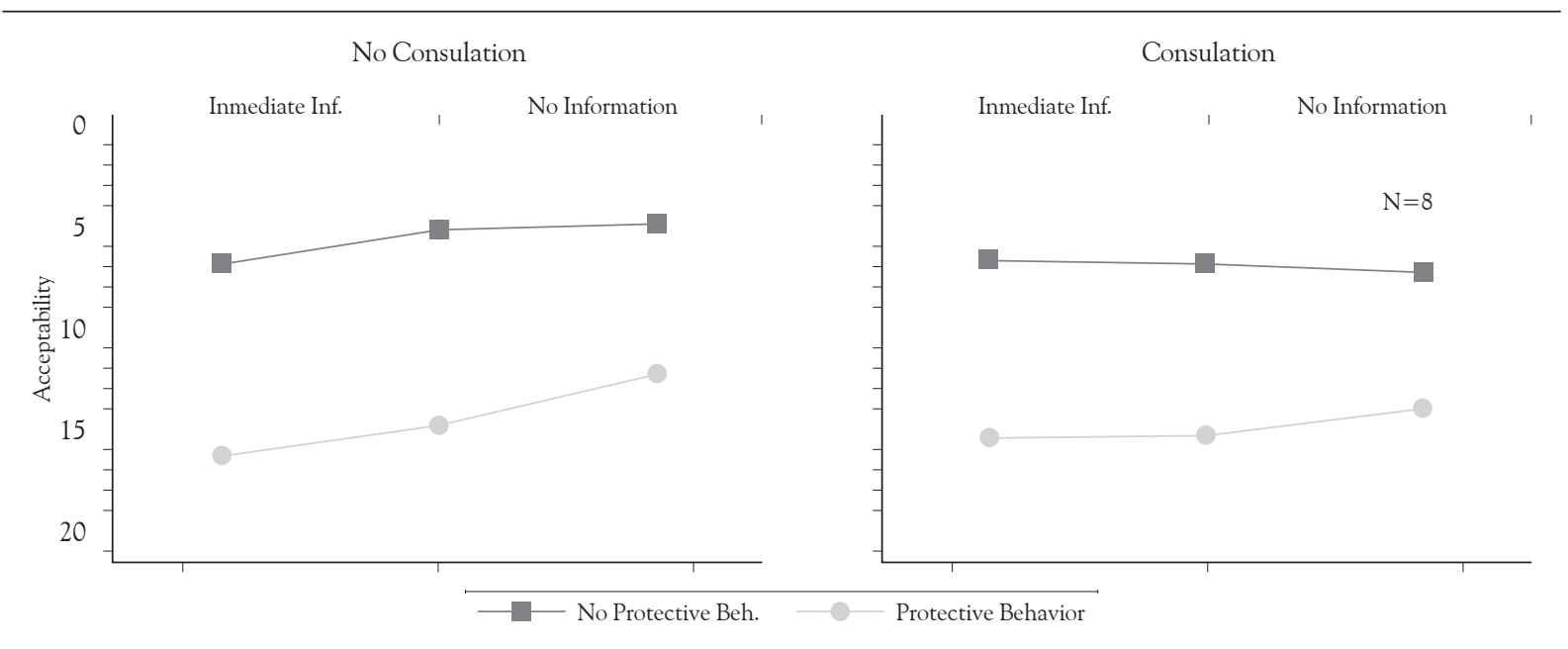




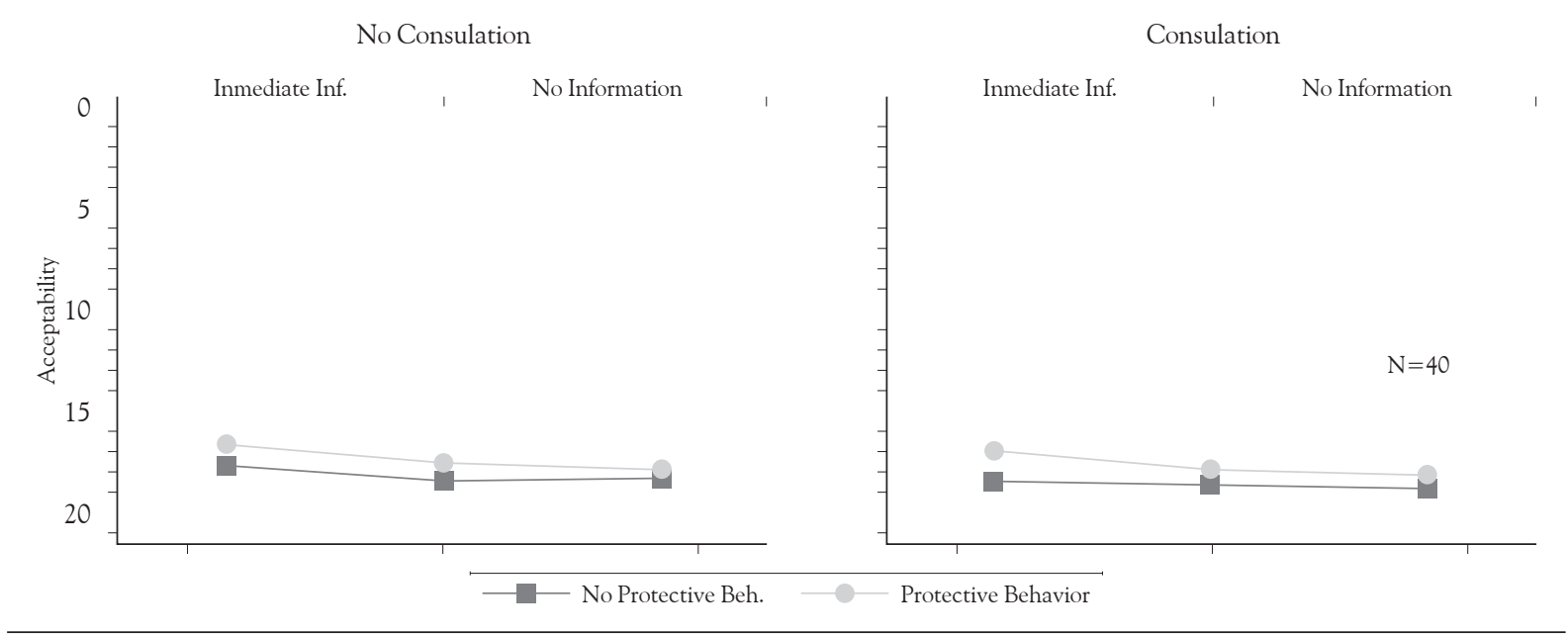

Source: Own work.

The fifth cluster was called Always acceptable. As can be seen in Figure 2 (bottom panels), the mean acceptability rating of the participants in this cluster was close to the right anchor of the acceptability scale. The percentage of Chilean participants in this cluster (12\%) was similar to that of French participants (10\%).

Finally, an ANOVA was conducted on the whole set of data. The design was Country x Gender $\mathrm{x}$ Age $\mathrm{x}$ Expert $\mathrm{x}$ Protection $\mathrm{x}$ Information $\mathrm{x}$ Time $x$ Severity, $2 \times 2 \times 2 \times 2 \times 3 \times 2 \times 2$, where Age was entered as a continuous variable. As we were only interested in the effect of the three betweensubject factors, the significance threshold was set at $0.05 / 3=0.016$. None of these three factors had a significant effect. Their effect sizes were always lower than 0.015 .

\section{Discussion}

This study of the acceptability among Chilean and French people of breaking confidentiality in a complex medical situation--namely when a patient might give his wife a serious STD--provided some new results. Firstly, for a large majority of lay people $(77 \%)$ and health professionals (70\%) in Chile, all of the five factors that were studied had direct effects on the acceptability of breaking confidentiality. In order of importance, these were (a) the patient's intention to adopt protective behavior, (b) the patient's intention to inform the person at risk (the patient's spouse), (c) the severity of the risk (i.e., of the consequences of acquiring the STD), (c) the physician's consultation with an expert, and (d) the time taken to talk with the patient about the severity of the disease. The time talking with the patient had more impact on the acceptability of informing the spouse if the patient was unwilling to adopt a protective behavior than if the patient appeared willing to do so. The following equation can be offered as a synthesis of these results:

Acceptability $=f[($ Protection $\mathrm{x}$ Time $)+$ Information + Severity + Consultation with expert] (1)

In other words, most lay people and health professionals in Chile appear to think in accordance with Chilean laws and professional codes of ethics.

Secondly, for a substantial minority of lay people $(12 \%)$ and health professionals $(11 \%)$ in Chile, informing the patient's spouse in case of the presence of a STD in the patient was considered as acceptable irrespective of the patient's attitude and of the severity of the infection. These persons appeared to consider that, in this case, disclosure was always necessary to avoid serious harm to the other person. In other words, they probably differed from the majority only in interpreting the dictates of Chilean law and professional ethics in a stricter way (see also, Zinn, 2003). 
Thirdly, more French lay people (10\%) than Chilean (2\%) believed that breaking confidentiality was not acceptable in any of the cases, in accordance with French law. Nonetheless, what is more striking, in support of our first hypothesis, is the similarity in views of the vast majority of the lay people in both countries.

Fourthly, in support of our second hypothesis, Chilean and French health professionals' attitudes differed greatly. Only one of ten Chilean physicians and one of seventeen Chilean psychologists considered breaking confidentiality as never acceptable versus six of seven French physicians and four of ten French psychologists. Thus the health professionals in both countries, in contrast to the lay people, held views about patient confidentiality that were in accordance with the different laws and codes of professional ethics of the two countries.

One additional finding deserves comment. For few lay people, mainly females, in Chili and France, the more the patient intended to inform and protect his spouse, the more acceptable was the breaking of confidentiality. They may have reasoned that if the patient was really willing to inform his spouse, revealing the infection would, for the physician, no longer involve breaking confidentiality. A similar attitude from a small group of patients had, in another context, already been found by Guedj et al. (2009).

In summary, codes of medical ethics appear to strongly impact on physicians' views about concrete ethical issues. Most French physicians adhere to the view that breaking patient confidentiality is never acceptable, which is the official position of the Ordre des Médecins in France. Most Chilean physicians adhere to the view that breaking patient confidentiality may be acceptable, which is the official position of the Colegio Médico in Chile (and in many other countries like the US and the United Kingdom). By contrast, codes of ethics do not appear to be strongly associated with lay people's views about the same ethical issues. Few lay French people, as well as a few Chileans, seem to believe that breaking patient confidentiality is never acceptable. Most French and Chilean people seem to adhere to the view that breaking patient confidentiality may, under certain conditionssuch as when a patient seems likely to transmit a serious STD to his wife--be acceptable, and even desirable.

Guedj et al. (2006) had offered several speculations to explain why French physicians were so different from French lay persons. The first speculation was that the scenarios were specifically about physicians; the physician participants had to imagine themselves in such a situation, whereas the lay people had to imagine others. The present findings run clearly counter to this explanation: most Chilean physicians in the sample agreed with the view that the breaching of confidentially can be acceptable.

The second speculation was that medical students and doctors in France are repeatedly taught about the importance of confidentiality; it has achieved almost sacred status. The third speculation was that physicians are at risk of losing the right to practice if condemned for violating the code of medical conduct, and in France the body responsible for this oversight, the Ordre des Médecins, is adamant about patient confidentiality. These two speculations are in accordance with the present findings. When, in a country like Chile, the law explicitly states as legitimate the breaching of confidentiality in some clearly delimitated cases (e.g., for very contagious illnesses or to avoid severe harm to other persons), most physicians agree with this position. They know that the law would protect them from malpractice suits from patients.

The fourth speculation was that busy physicians tend to want to restrict their responsibilities to the specific issues at hand-the particular patient in their office and the individual physical and, in some cases, psychological dimensions of this patient's illness - rather than take on the broader and time-consuming tasks that might be performed by a social worker or public health official. The present findings run counter to this explanation.

The major determinant of physicians' attitudes toward breaking confidentiality seems, therefore, to be the dictates of the medical code of ethics and the law. If the code of ethics of France's Ordre des Médecins was similar that governing Chilean phy- 
sicians (as well as British and US physicians), it is likely that French physicians would behave in the same way as their foreign colleagues; that is, they would conform with their duty to rescue.

\section{Limitations}

The study has several limitations. First, the participants were limited to people in the regions of BíoBío and Maule, Chile, and Toulouse, France. Generalizations to other areas and to other countries must, therefore, be done with care. It is, however, reassuring that no strong effect of age or gender was detected; this means that the results are probably robust ones. Second, the samples of health professionals were small in size: In particular, it was difficult to convince physicians to participate in the study. The study findings need to be confirmed, therefore, on other samples.

Third, the ratings were made about hypothetical scenarios rather than real cases. Fourth, the importance of factors partly depends on the way they are phrased. For example, the severity of the risk could have had a somewhat greater impact if we had explicitly labeled the more serious infection as "HIV-AIDS." Fifth, multiple other factors may influence, of course, the decisions of individual physicians and patients, even though, as stated in the introduction, previous work suggested that the factors we studied have wide generalizability.

In spite of these limitations, our findings should make physicians and policy makers be aware that, in Chili as well as in France, most people-including patients, voters, and jury members-are sensitive to the influence of situational factors on the difficult moral decision about whether or not a physician should break confidentiality when he or she suspects that a patient may cause harm to someone else. Trust in the medical profession is unlikely to be undermined if from time to time, individual physicians decide to break confidentiality when facing dilemmas of this kind. People well understand that by doing so, health professionals demonstrate that they value life above any other consideration (Zinn, 2003).

\section{References}

Anderson, N. H. (2008). Unified social cognition. New York: Psychology Press.

Conseil National de l'Ordre des Médecins. (1996). Code de Déontologie Médicale [Commentary by L. René]. Paris: Seuil.

Conseil National de l'Ordre des Médecins. (2002). Bulletin de l'Ordre. Paris: Author.

Chile, Código Penal. (2008). Santiago: Editorial Jurídica.

Chile, Código Procesal Penal. (2009). Santiago: Editorial Jurídica.

Chile, Colegio Médico. (2008). Código de Ética. Accessed 16 October, 2009. Available at http://www. colegiomedico.cl/Default.aspx?tabid $=248$

DiMarco, M. \& Zoline, S. (2004). Duty to warn in the context of HIV/AIDS-related psychotherapy: Decision-making among psychologists. Counseling and Clinical Psychology Journal, 1 (2), 68-85.

Edelstein, L. (1943). From the Hypocratic Oath: Text, translation and interpretation. Baltimore: John Hopkins Press.

France, Nouveau Code Pénal. (2002). Paris: Dalloz.

Fruchart, E., Rulence-Pâques, P. \& Mullet, E. (2007). Ecological validity test of laboratory studies on information integration [Special Issue on Functional Measurement]. Teorie Ë Modelli, 12 (1-2), 281-288.

Guedj, M., Muñoz Sastre, M. T., Mullet, E. \& Sorum, P. C. (2006). Under what conditions is the breaking of confidentiality acceptable to lay people and health professionals? Journal of Medical Ethics, 32, 414-419.

Guedj, M., Muñoz Sastre, M. T., Mullet, E. \& Sorum, P. C. (2009). Is it acceptable for a psychiatrist to break confidentiality to protect a wife from violence? International Journal of Law and Psychiatry, $32,108-114$.

Jones, C. (2003). The utilitarian argument for medical confidentiality: A pilot study of patients' views. Journal of Medical Ethics, 29(6), 348-52.

Keffala, V. \& Stone, G. (1999). Role of HIV serostatus, relationship status of the patient, homophobia and social desirability of the psychologist on the decisions regarding confidentiality. Psychology $\mathbb{E}$ Health, 14(4), 567-584. 
Levin, I. P., Louviere, J. J., Schepanski, A. A. \& Norman, K. L. (1983). External validity test of laboratory studies of information integration. Organizational Behavior and Human Performance, 31 (2), 173-193.

McGuire, J., Nieri, D., Abbott, D. \& Sheridan, K. (1995). Do Tarasoff principles apply in AIDSrelated psychotherapy? Ethical decision making and the role of therapist homophobia and perceived client dangerousness. Professional Psychology: Research EF Practice, 26(6), 608-611.

Ministerio de Salud de Chile. (2001). Ley 19.779, que establece normas relativas al VIH y crea bonificación fiscal para enfermedades catastróficas. Accessed 16 October, 2009. Available at http://www.leychile. cl/Navegar?idNorma $=192511$

Moatti, J. P., Souville, M., Obadia, Y., Morina, M., Sebbah, R., Gamby, T. et al. (1995). Ethical dilemma in care for HIV infection among French general practitioners. Health Policy, 31 (3), 197-210.

Muñoz Sastre, M. T., González, C., Lhermitte, A., Sorum, P. C. \& Mullet, E. (2010). Do ethical judgments depend on the type of response scale? Comparing acceptability versus unacceptability judgments in the case of Life-Ending procedures. Psicológica International Journal of Methodology and Experimental Psychology, 31 (3), 529-539.

Muñoz Sastre, M. T., Pecarisi, C., Legrain, E., Mullet, E. \& Sorum, P. C. (2007). Acceptability in France of induced abortion for adolescents. American Journal of Bioethics, 7(8), 26-32.

Stewart, T. M. \& Reppuci, N. D. (1994). AIDS and murder: Decisions regarding maintenance of confidentiality versus the duty to protect. Law and Human Behavior, 18(2), 107-120.

Teisseyre, N., Mullet, E. \& Sorum, P. C. (2005). Under what conditions is euthanasia acceptable to lay people and health professionals? Social Science and Medicine, 60(2), 357-368.

Totten, G., Lamb, D. H., \& Reeder, G. D. (1990). Tarasoff and confidentiality in AIDS-related psychotherapy. Professional Psychology: Research and Practice, 21 (3), 155-160.

Zinn, C. (2003). Wife wins case against GP's who did not disclose husband's HIV status. British Medical Journal, 326(7-402), 1286-1287. 


\section{Appendix}

\section{Two Examples of Scenarios}

Mr. Sastre comes to see Dr. López. The results of analyses show that Mr. Sastre is currently infected with a sexually transmitted disease. Given the current state of our knowledge, the consequence of this infection will, after a medium amount of time, be fatal.

Dr. López mentions only briefly to Mr. Sastre the consequences of this infection, the risks of spreading it, and the precautions that can be taken against spreading it. Mr. Sastre manifests, during the visit, his intention not to mention his state of health to his spouse.

It appears to Dr. López that Mr. Sastre will do nothing to protect his spouse during sexual relations.

Worried about the health of Mr. Sastre's wife, Dr. López decides to call her and keep her informed about her husband's infection and about the risks incurred. Before taking this step, Dr. Lopez takes the precaution of requesting the advice of Professor Labrador, a specialist in STD's.

To what extent do you believe that the decision made by Dr. López is acceptable?

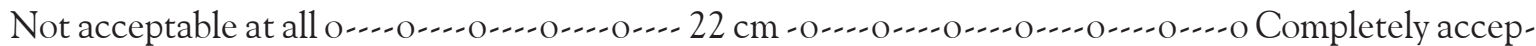
table

Mr. Molina comes to see Dr. Olivari. The results of analyses show that Mr. Molina is currently infected with a sexually transmitted disease. Given the current state of our knowledge, the consequences of this infection will not be fatal but will nonetheless be very serious.

Dr. Olivari spends much time in discussing with Mr. Molina the consequences of this infection, the risks of spreading it, and the precautions that can be taken against spreading it. Mr. Molina manifests, during the visit, his intention of telling his spouse immediately about his state of health.

It appears to Dr. Olivari that Mr. Molina will do everything to protect his spouse during sexual relations.

Still worried about the health of Mr. Molina's wife, Dr. Olivari decides, nevertheless, to call her and keep her informed about her husband's infection and about the risks incurred. It is a decision that Dr. Olivari makes by himself.

To what extent do you believe that the decision made by Dr. Olivari is acceptable?

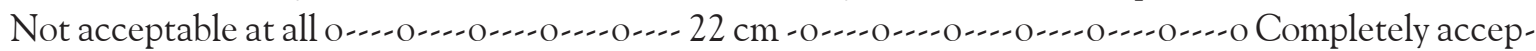
table 